\title{
Na produtiva confluência entre educação e comu- nicação, as pedagogias culturais contemporâneas
}

\author{
Marisa Vorraber Costa* \\ Paula Deporte de Andrade**
}

\section{Resumo}

O artigo apresenta uma discussão sobre a produtividade do conceito de pedagogias culturais em estudos brasileiros que aproximam educação e comunicação. Analisa-se, em teses e dissertaçóes, como os pesquisadores operam com o conceito e o que conseguem mostrar acerca dos modos como se engendram as pedagogias que formam os sujeitos do presente. $\mathrm{O}$ corpus de análise foi composto por doze trabalhos coletados no banco de teses e dissertaçôes da CAPES. O referencial teórico do estudo é subsidiado por autores que tratam de pedagogia e de pedagogias culturais, como Jorge Larrosa (1994), Steinberg e Kincheloe (2004), Giroux (1994), Fischer (1997), Camozzato (2012), dentre outros. Os resultados da análise foram aglutinados em três modos de operação das pedagogias culturais apontados nas pesquisas investigadas: a) representação de modos de ser sujeito; b) acionamento de complexo mercantil midiático; c) acionamento de técnicas de cuidados de si.

Palavras-chave: Comunicação e Educação. Pedagogias culturais. Mídia e Educação.

* Doutora em Educação pela Universidade Federal do Rio Grande do Sul (UFRGS). Professora da Universidade Luterana do Brasil (ULBRA) e docente convidada do Programa de Pós-Graduaçáo em Educação da Universidade Federal do Rio Grande do Sul (UFRGS).

** Mestre em Educação pela Universidade Luterana do Brasil (ULBRA) e Doutoranda em Educação na Universidade Federal do Rio Grande do Sul (UFRGS). 


\section{Introdução}

Há mais de dois mil anos, a ideia de que nos constituímos como pessoas no contato orgânico com as culturas em que nos inscrevemos acompanha a história do Ocidente. Já no mundo grego clássico e helenístico, o ideal de formaçáo humana, a paideia, concebia educação e cultura entrelaçadas em um processo que abarca a totalidade da vida. A historiografia contemporânea da Educação tem provocado transformaçóes profundas nas visôes do mundo antigo, sublinhando que, desde os primórdios, as relaçôes entre cultura e educação foram matizadas por tensôes, contrastes e dissonâncias (CAMBI, 1999). Mas o conjunto de saberes sobre como e o que se deve ensinar, como se aprende, como deve ser organizado o ensino, e outras questóes correlatas, vai se estruturar no mundo europeu a partir do século XVI, rompendo com concepçóes e práticas vigentes na antiguidade greco-romana e na era medieval. Jan Amos Comenius ${ }^{1}$ é conhecido como inventor do discurso pedagógico moderno, que revoluciona a educaçáo no século XVII, ao instaurar novos modos de pensar sobre as relaçóes educativas.

Após aproximadamente quatro séculos, consideráveis resquícios da pedagogia comeniana ${ }^{2}$ persistem nas concepçóes contemporâneas, embora as profundas transformaçóes socioculturais e políticas verificadas desde o final do século XIX e ao longo do século XX tenham abalado irremediavelmente também este monólito teóricoconceitual e metodológico denominado pedagogia moderna. Outras formas de conceber a educaçáo e a pedagogia, novas maneiras de pensar sobre elas e também de colocá-las em funcionamento emergiram sob a condição pós-moderna; especialmente as teorizações ditas pós-estruturalistas, pós-críticas ou pós-metafísicas têm fornecido ferramentas teóricas para a análise de tais formas de pensar e tais modos de operaçáo.

Larrosa (1994, p. 36), inspirado em trabalhos de Michel Foucault que abrem possibilidades para se explorar outras maneiras de pensar, dá especial atenção, no espectro de práticas consideradas pedagógicas, àquelas em que "se produz ou se transforma a experiência que as pessoas têm de si mesmas". Em tais práticas, importam menos as aprendizagens do "exterior" e mais as relaçôes reflexivas dos sujeitos consigo mesmos. Desse ponto de vista, a pedagogia realiza operaçôes constitutivas, fabrica ativamente indivíduos, molda sujeitos, e se pode pensar a educação e a pedagogia como o processo histórico de transformação de cada um de nós naquilo que somos. Por seu caráter constitutivo, a pedagogia, de acordo com Larrosa (1994), tem sido uma das tecnologias mais produtivas na regulação de sujeitos. Entendida como uma prática cultural cujos objetivos voltam-se para a modificação dos modos de ser sujeito, não pode ser considerada como um espaço neutro ou de simples mediaçáo. Ela é um espaço 
de construção e atua "produzindo formas de experiência de si nas quais os indivíduos podem se tornar sujeitos de um modo particular" (LARROSA, 1994, p. 57). O autor argumenta ainda que as instâncias pedagógicas que fazem com que os sujeitos incidam sobre si mesmos atuam como dispositivos pedagógicos e "um dispositivo pedagógico será, então, qualquer lugar no qual se constitui ou se transforma a experiência de si. Qualquer lugar no qual se aprendem ou se modificam as relaçóes que o sujeito estabelece consigo mesmo" (LARROSA, 1994, p. 57).

Neste panorama, o presente artigo apresenta um recorte de pesquisas que vimos realizando inspiradas em uma concepçáo de educaçáo como vontade de governar, de moldar e dirigir condutas, em que pedagogias são praticadas em distintos espaços e contextos. Consideramos que, atreladas a objetivos sociais emergentes, uma multiplicidade de pedagogias toma corpo e entra em operação, especialmente nos meados da segunda metade do século XX. Diversificados espaços e artefatos culturais estão hoje implicados tanto nas formas como as pessoas pensam e agem sobre si mesmas e sobre o mundo que as cerca como nas escolhas que fazem e nas maneiras como organizam suas vidas. Nas complexas sociedades do mundo globalizado, pedagogias são praticadas também por jornais, programas de TV, peças publicitárias, filmes, revistas, sites e inúmeros outros artefatos que atravessam a vida contemporânea. Como argumentam Giroux e McLaren (1995, p. 144), "existe pedagogia em qualquer lugar em que o conhecimento é produzido, em qualquer lugar em que existe a possibilidade de traduzir a experiência e construir verdades". A pedagogia não é, entấo, privativa das práticas escolares, religiosas e familiares. Segundo Camozzato e Costa (2013a; 2013b), há hoje uma proliferaçáo e pluralização das pedagogias, expressão de um refinamento das artes de governar, regular e conduzir sujeitos.

O campo dos Estudos Culturais em Educação tem sido um espaço intelectual dedicado a examinar estes novos lugares de produção de sujeitos, sendo o controvertido conceito de pedagogias culturais uma das ferramentas teóricas de grande utilidade. De acordo com o vocabulário de teoria cultural de Silva (2000, p. 89), "qualquer instituição ou dispositivo cultural que, tal como a escola, esteja envolvido - em conexão com relaçôes de poder - no processo de transmissão de atitudes e valores [...]" pode ser entendido como uma pedagogia cultural. A compreensão de que diferentes artefatos da cultura são produtivos na formaçáo dos sujeitos encontrou nos Estudos Culturais e nas discussóes e análises sobre pedagogias culturais fundamentação teórica e empírica pertinente. Com isso, novas e instigantes discussôes sobre esta hibridação entre Educação e Comunicação começaram a ser produzidas, uma vez que os artefatos da cultura contemporânea provavelmente mais implicados na formação de sujeitos são midiáticos, como textos televisivos, jornalísticos, radiofônicos, publicitários, 
fotográficos, fílmicos, assim como aqueles das assim chamadas novas mídias, conectadas a world web wide.

Nessa perspectiva, interessamo-nos em discutir como tem sido produtivo, para os dois campos, o debate dos Estudos Culturais resultante desta aproximação entre Educação e Comunicação, no qual o conceito de pedagogias culturais é ferramenta amplamente acionada nas análises. Sendo assim, este artigo apresenta e problematiza os resultados de um projeto de pesquisa que teve como um de seus objetivos analisar, em um conjunto de teses e dissertaçóes, como os pesquisadores operam com o conceito e o que conseguem mostrar acerca dos modos como se engendram as pedagogias que formam sujeitos do tempo presente.

Para compor o corpus de análise, tomamos como fonte de pesquisa o banco de teses e dissertaçóes da CAPES, utilizando como critério inicial de busca a palavra-chave pedagogia cultural ou pedagogias culturais. Identificamos mais de cem trabalhos nesta primeira aproximação. Em seguida, restringimos esta primeira seleção para aqueles que além de uma das expressóes mencionadas incluísse outra palavra-chave que fizesse referência a artefatos de comunicação como mídia, revistas, jornal, filme e similares. Com este refinamento de busca, localizamos doze estudos, sendo onze dissertaçóes e uma tese ${ }^{3}$.

Discutimos, a partir dessas pesquisas, como as pedagogias culturais flexionam o entendimento sobre pedagogia, quais modos de operação são indicados como manifestaçôes de pedagogias e como isso contribui para se pensar sobre as aproximaçôes entre Educação e Comunicação.

\section{Pedagogias culturais: nos rastros do conceito}

Como já exposto, a noção de pedagogias culturais integra o referencial teóricoconceitual dos Estudos Culturais em Educação. Contudo, se o próprio campo dos Estudos Culturais ainda persiste controvertido quanto a seu estatuto epistemológico e científico, com as pedagogias culturais não é diferente. Para chegar ao conceito com os usos que tem hoje, muitas discussôes sobre a pedagogia e suas relaçốes com a cultura foram e continuam sendo necessárias.

Aproximamo-nos desses debates mediante levantamento bibliográfico, e localizamos o livro Cultural Pedagogy: arts, education, politics, do norte-americano David Trend, lançado em 1992, como sendo provavelmente a primeira obra acadêmica em que é utilizado o conceito pedagogia cultural. Neste livro (cujo prefácio foi escrito por Henry Giroux), o autor traz à discussão os diferentes percursos que possibilitaram tanto que a cultura tomasse a dimensáo de uma dominante quanto o papel da 
pedagogia nesta movimentação. A partir das articulaçôes entre cultura e pedagogia, ele vai apontando as lutas teóricas que conduziram ao entendimento que temos hoje sobre pedagogias culturais.

Os deslocamentos nos dois conceitos aí implicados - pedagogia e cultura - são muito produtivos para pensar o tempo presente. Segundo Trend (1992), a importância da cultura no campo social começa a ser discutida pelos marxistas da Escola de Frankfurt. Horkheimer e Adorno, na década de 1930, não teriam dado à cultura sua merecida importância, mesmo considerando que os artefatos da indústria cultural cativavam as massas e as incentivavam ao consumo. De acordo com Trend (1992), foi só posteriormente, a partir das ideias de Althusser sobre o papel da cultura na complexa relação dialética com o mercado, e, na década de 1970, com os estudos do também marxista Enzenberger - discordante em relaçáo ao entendimento de cultura de seus antecessores de esquerda-, que novos modos de olhar para a cultura foram produzidos. Para Enzenberger (apud TREND, 1992, p. 12), "em vez de enganar as massas em uma rede de falsos desejos, a mídia realmente encontrou maneiras de satisfazer reais (mas muitas vezes inconscientes) desejos". Mais tarde, marxistas pós-estruturalistas, como Jameson e Barthes, afirmariam que as possibilidades de significação eram negociáveis e que os sinais culturais podem ser interpretados de diferentes formas.

Com as lutas sociais travadas após a segunda Guerra Mundial, emergiram outros estudos que também contribuíram para se pensar a relação da pedagogia com a cultura. Dentre estes, Trend (1992) destaca os estudos de Gramsci ${ }^{4}$ e Bourdieu, assim como os trabalhos de Giroux sobre a teoria crítica. Para ele, os escritos de Gramsci são pioneiros no que se refere à multiplicaçấo dos locais de aprendizagem. Considerando as mudanças sociais como processos de aprendizagem, Gramsci argumentava, diferentemente de Marx, que toda relação de hegemonia é necessariamente uma relação educativa, concepção que admite serem os aparatos do Estado (igreja, museu e até as mídias) instrumentos de persuasão ideológica e, portanto, processos pedagógicos.

Os trabalhos de Bourdieu, por sua vez, ao apontarem as complexas e intrínsecas relaçôes entre a luta por status social e o uso de bens culturais por diferentes grupos, teriam trazido avanços ao ampliar o entendimento sobre o papel da cultura. Com esses e outros estudos, abriu-se caminho para uma nova teoria: a teoria crítica da educação, e começou-se a dar atenção ao caráter político dos espaços pedagógicos. Conforme Trend (1992, p. 25), "isso significa admitir que muitas áreas que reivindicam neutralidade em nossas vidas são, de fato, locais de lutas ideológicas profundas". Currículos escolares, programas de rádio e televisão, entre vários outros, são artefatos que expressam formas de representação produzidas a partir de interesses específicos.

Um dos expoentes da pedagogia crítica, Giroux (1994), no artigo Doing cultural studies: youth and the challenge of pedagogy, esclarece que compreende as 
pedagogias críticas não apenas como um conjunto de técnicas e habilidades, mas como uma prática cultural. Aproximando-se dos Estudos Culturais, o autor buscou relacionar tal campo e as pedagogias críticas, pois, para ele, os Estudos Culturais oferecem uma teorização importante aos educadores já que aportam elementos tanto para analisar a produção histórica, econômica e cultural de representaçôes e desejos que os jovens contemporâneos absorvem, especialmente pela mídia, quanto para repensar a relação entre poder, cultura, aprendizagem e o papel dos docentes como "intelectuais públicos" (GIROUX, 1994).

Além de salientar as conexôes entre educação e cultura, Giroux, em vários textos da década de 1990, aproximou Educação e Comunicação. A partir da análise de artefatos midiáticos, como filmes hollywoodianos e desenhos animados da Disney, o autor destacou que tais artefatos, ao mesmo tempo em que reforçam estereótipos de gênero e raça, dáo condiçôes para que, mediante uma pedagogia crítica, tais narrativas sejam reescritas por meio do desenvolvimento de mecanismos de resistência contra os discursos dominantes.

Acoplado à Pedagogia Crítica, surge o conceito de "política cultural" (SIMON, 20085; GIROUX, 2008 $)$, utilizado especialmente para reforçar que o processo de escolarização está imbricado nas produçôes culturais de dois modos: por meio da "distribuição diferencial de conhecimento e recompensas simbólicas entre diferentes grupos de pessoas" (SIMON, 2008, p. 67); e por meio do reconhecimento de que as escolas "estão inevitavelmente presas na relação inseparável entre cultura e poder" (SIMON, 2008, p. 67). Com isso, afirma-se que a escola e o trabalho pedagógico são políticos, pois estão em conexão com os interesses, com as relaçôes de saber e poder de determinada cultura.

Antes de esses autores adotarem a expressão pedagogias culturais, pelo menos outras duas foram empregadas. A primeira foi "pedagogia popular", mas revelou-se problemática por poder sugerir que uma pedagogia das massas seria uma pedagogia inferior, caindo em desuso assim que as discussóes pós-modernas romperam as fronteiras entre "alta" e "baixa" cultura. Outra expressão foi a cunhada por Simon (2008) e denominada "tecnologias culturais". Com o objetivo de ampliar a noção de pedagogia, o conceito refere-se "a conjuntos de arranjos e práticas institucionais intencionais no interior dos quais várias formas de imagens, som, texto e fala são construídas e apresentadas, e com as quais, ademais, interagimos" (SIMON, 2008, p. 71). O autor afirma que outros espaços, para além da escola, desenvolvem tais tecnologias, como "o cinema, o teatro, a televisão, a publicidade, a arquitetura, os fóruns de saúde pública, o jornalismo impresso, a música popular, os festivais onde se contam histórias e os estudos e rituais religiosos" (SIMON, 2008, p. 72). 
Em 1997, Steinberg e Kincheloe (2004), inspirados nos escritos de Giroux sobre pedagogia e mídia, e também influenciados pelas teorizaçôes da pedagogia crítica, organizaram o livro Kinderculture: the corporate construction of childood ${ }^{7}$. Nesta obra, discutem a produtividade da mídia na construção corporativa da infância, uma infância pautada por e para o consumo. Empregam o conceito de pedagogias culturais para aludir à formataçáo das crianças pelos diversos artefatos midiáticos, uma infância que denominam de pré-fabricada - a infância construída por grandes corporaçóes como Mattel, Disney e McDonald's.

Esse entendimento contemporâneo sobre pedagogias culturais, adotado e propagado especialmente por Giroux (2008), Steinberg e Kincheloe (2004), é compartilhado pelos pesquisadores dos Estudos Culturais, mas também dos Estudos de Gênero, de Mídia etc. Contudo, parece ter sido na década de 1990, particularmente na Faculdade de Educação da Universidade Federal do Rio Grande do Sul, com a criação da linha de pesquisa Estudos Culturais em Educação, que o conceito de pedagogias culturais começou a ser usado no Brasil como ferramenta teórica do campo da educaçáo. Ripoll (apud WORTMANN, 2010, p. 15) avalia que "foi a partir do uso intenso desse conceito - em dissertaçóes e teses -, que pudemos articular (mais explícita e firmemente) a nossa vontade de pesquisar as novas configuraçóes culturais contemporâneas ao campo educacional”.

Partindo disso e compreendendo que o conceito de pedagogias culturais tem sido uma ferramenta importante para que pesquisadores articulem cultura, educaçáo e comunicação em estudos que visam problematizar a fabricação de sujeitos do tempo presente, buscamos mostrar nos trabalhos analisados neste recorte de pesquisa: a) como os pesquisadores brasileiros utilizam o conceito de pedagogias culturais; b) quais autores subsidiam os estudos; c) quais são as principais formas de operação das pedagogias culturais evidenciadas por estes trabalhos.

\section{Pedagogias culturais, Educação e Comunicação}

Acessando o banco de teses e dissertaçóes da CAPES e colocando como palavras-chave as expressóes pedagogia cultural e pedagogias culturais surgiram dezenas de pesquisas que utilizam tal ferramenta teórica. Dentre elas, localizamos doze que mencionavam as duas palavras-chave que procurávamos-pedagogia(s) cultural(is) mais mídia, imagem, ou a denominação de algum artefato de comunicação como cinema, jornal etc.. Tais estudos compóem o corpus desta análise.

No material coletado, constatamos que os mais variados artefatos midiáticos já foram objeto de análise: revistas, filmes, jornais, publicidade, novelas e desenhos 
animados. Os trabalhos foram produzidos em cinco Programas de Pós Graduação ${ }^{8}$ da regiáo sudeste e sul, mais concentradamente no Rio Grande do Sul. Observamos que os primeiros resultados das aproximaçôes do campo dos Estudos Culturais em Educação com o da Comunicação surgem em 2002, mas a maior concentração está nos anos 2009, 2010 e 2011.

$\mathrm{Na}$ análise das pesquisas propriamente ditas, constatamos que os autores fazem uso do conceito de pedagogias culturais por considerarem-no produtivo para pensar os efeitos pedagógicos de seu objeto de análise. Em capítulos ou seçóes intituladas "Educação e Imagem: uma interface da Pedagogia Cultural" (CARVALHO, 2002), "Mídia e consumo como pedagogia cultural" (FLOR, 2007), "Cinema enquanto Pedagogia Cultural” (CARVALHO 2011), "O Cinema Novo no Brasil - Uma Pedagogia Cultural Militante" (SILVA, 2010), "Recortes sobre os Estudos Culturais, Identidades e as Pedagogias culturais" (SANTOS, 2011), os autores ressaltam a produtividade formativa dos artefatos da cultura quando Educação e Comunicação se aliam no tempo presente.

Nestas seçóes sobre Pedagogias Culturais, os pesquisadores evidenciam o quanto os artefatos da Comunicação educam, regulam condutas, subjetivam. De acordo com Figueira (2003, p. 15), as pedagogias de hoje ensinam "comportamentos, hábitos, valores e procedimentos considerados adequados, utilizando-se, para tanto, de diferentes artefatos culturais como o cinema, a televisão, as revistas, a literatura, a moda, a publicidade, a música”. Silva (2010, p. 39), ao estudar o Cinema Novo, afirma que "deliberadamente, o Cinema Novo pretende unir arte e política com a pretensão de fazer do cinema um instrumento pedagógico de conhecimento e de intervençáo na realidade nacional". Já Santos (2011, p. 53), ao analisar a revista Indústria Brasileira, constata que "Em certo sentido, a revista IB mostra-se também como um artefato pedagógico que produz e coloca em circulação algumas representaçôes acerca de como a indústria brasileira deve ser [...]".

Em termos de referencial teórico, observamos que a maioria dos autores que subsidiam os pesquisadores faz parte de uma mesma linha de compreensão e interpretação dos efeitos das pedagogias culturais, de uma mesma corrente de estudiosos cujos trabalhos fazem interlocução entre si, e cujos autores mencionam os achados das pesquisas de seus pares. Kellner (2001, 2008), Giroux (2008), Giroux e McLaren (1995) e Steinberg e Kincheloe (2004) são os autores de obras estrangeiras mais citados nos trabalhos analisados.

Além disso, merece menção o fato de ser o livro de Silva (2008), Alienígenas na sala de aula: uma introdução aos Estudos Culturais em Educação, uma referência constante. Lançada em 1995, a obra é considerada o primeiro livro de Estudos 
Culturais em Educação publicado no Brasil e aquele que introduz esses debates no meio acadêmico da educação. Nele estão traduzidos os primeiros artigos que fazem referência às Pedagogias culturais, de Simon (2008), Giroux (2008) e Kellner (2008) recorrentemente citados nas pesquisas.

Para estreitar ainda mais a relação entre Educação e Comunicação, dois autores destacam-se: de Kellner (2001, p. 9), o livro A cultura da midia-Estudos Culturais: identidade e política entre o moderno e o pós-moderno é utilizado especialmente para ressaltar que os meios de comunicaçáo compóem o que o autor denomina cultura da mídia, cultura que é industrial, comercial, dirigida às massas e atuante no tecido social, "dominando o tempo de lazer, modelando opiniôes políticas e comportamentos sociais, e fornecendo o material com que as pessoas forjam suas identidades"; e a tese de Fischer (1997) sobre como a mídia atua na produção dos sujeitos adolescentes, assim como seus artigos posteriores, na mesma linha de pensamento, que evidenciam e argumentam acerca do estatuto pedagógico da mídia e seus efeitos sobre a produção dos sujeitos, serviram como referência para trabalhos em que as análises se aproximam dos estudos foucaultianos. Segundo Fischer (1997, p. 61):

As diversas modalidades enunciativas (tipos e gêneros específicos de enunciação audiovisual) dos diferentes meios e os produtos de comunicação e informação - televisão, jornal, revistas, peças publicitárias -, parecem afirmar em nosso tempo o estatuto da mídia não só como veiculadora, mas também como produtora de saberes e formas especializadas de comunicar e de produzir sujeitos, assumindo desse jeito uma função nitidamente pedagógica.

Autores internacionais e brasileiros, enfoques ora mais culturalistas, ora mais foucaultianos da produtividade dos artefatos da mídia na construção de representaçóes e de modos de ser, subsidiam as pesquisas sobre os modos como as pedagogias culturais operam. No conjunto de trabalhos em que o conceito de pedagogias culturais é ferramenta teórica central, os pesquisadores conseguem mostrar não só os efeitos de tais pedagogias, mas os modos como são produzidos.

Para organizar os dados que coletamos, e decompor alguns elementos para análise, consideramos que há três modos predominantes, interligados e intercomplementares de operação destas pedagogias, conforme expomos a seguir.

\section{Pedagogias Culturais, representaçáo e valores}

Um primeiro modo observado refere-se à vertente em que o conceito de representação é central. É com ele que os pesquisadores procuraram demonstrar que ao 
representar determinados tipos de sujeito ou determinados tipos de comportamento, atribuindo-lhes um conjunto de significados, os artefatos midiáticos criam padróes, modelos desejáveis, que educam e produzem sujeitos constituídos segundo seus preceitos. Na perspectiva desses trabalhos: "A representação inclui as práticas de significação e os sistemas simbólicos por meio dos quais os significados são produzidos, posicionando-nos como sujeito. É por meio dos significados produzidos pela representação que damos sentido à nossa experiência e àquilo que somos" (WOODWARD, 2007, p. 17). Nesse sentido, os trabalhos argumentam que é por intermédio das imagens, discursos e narrativas postas em circulação por revistas, jornais, publicidades etc., que aprendemos a ser sujeitos de um certo tipo e é por meio da produção e circulação dessas representações que as pedagogias culturais operam. Galcowski (2011, p. 38) afirma que "somos educados, dentre outras formas, através da representação de papéis sociais e veiculação de sentidos praticada pela industrial cultural". Silva (2009, p. 19), ao estudar o artefato cinema, aponta que "a funçáo pedagógica do cinema está sempre presente", pois ao assistirem filmes os sujeitos "também aprendem valores e modos de ser a partir das representaçóes veiculadas". Também Santos (2011, p. 52), ao usar o conceito de representação atrelado ao de pedagogias culturais, afirma que "partir das representaçóes produzidas e veiculadas por tais artefatos (como as revistas e os jornais, que estão inseridos no conjunto de práticas da mídia) são reforçadas ou contestadas algumas 'verdades' acerca do mundo". Fensterseifer (2005, p.103-104) aponta que as Pedagogias culturais "têm efeitos educativos na construçáo das representaçóes de mundo e nos modos de ser sujeito", e destaca ainda que tais pedagogias "estabelecem-se através de 'jogos de poder' no qual há disputas na produção de significados".

Ou seja, os trabalhos onde a representação é salientada como elemento central no modo como as pedagogias culturais operam estáo, em maior ou menor grau, alinhados com os estudos de Kellner (2001, p. 9) sobre a cultura da mídia, nos quais argumenta que nesta cultura "o rádio, a televisão, o cinema e os outros produtos da indústria cultural fornecem os modelos daquilo que significa ser homem ou mulher, bem-sucedido ou fracassado, poderoso ou impotente". Isso significa também que tais representaçôes, conforme apontam Steinberg e Kincheloe (2004), estão conectadas a questóes mercantis já que, na contemporaneidade, cultura e consumo - seja este de objetos, seja de modos de vida - estão intimamente atrelados e sáo os motores do capitalismo contemporâneo, o que faz com que as pedagogias culturais estejam intensamente atreladas/alinhadas/direcionadas a fazer as pessoas consumirem. 


\section{Pedagogias Culturais e acionamento de complexos mercantis midiáticos}

Outro modo de operacionalizaçáo das pedagogias culturais emerge das vinculaçóes estreitas entre mídia e consumo. Nele, os pesquisadores apontam estratégias que articulam variados artefatos culturais para direcionar crianças e jovens ao consumo. Argumentam que, por intermédio da construção de um complexo mercantil midiático (brinquedos, filmes, CDs, vestuário, livretos, quadrinhos, adornos etc.), criase um universo de imagens atraentes que constantemente, e de maneiras sedutoras, convocam os sujeitos ao consumo.

Flor (2007) e Prates (2008) construíram seus objetos de estudos entendendo-os como "complexos" para lançar luz sobre um modo de formar consumidores que implica aglutinar um numeroso conjunto de artefatos a um acontecimento midiático gerador ou nuclear. Flor (2007) utiliza as metáforas de circuitos e teia para analisar o "Complexo Rebelde" (novela, banda musical, álbuns, roupas, shows de TV e ao vivo etc.) e explicar como as pedagogias culturais operam neste complexo midiático. De acordo com o pesquisador, o circuito gera renovadas explosóes de energia (cada novo acontecimento midiático espetacularizado) dentro do complexo, que atraem crianças e jovens; a teia, por sua vez, a cada nova explosão, captura estes jovens consumidores com sua variedade de produtos para seduzir, modelar e conduzi-los a novos atos de consumo. Assim, "a cada momento, induzidos pelo poder (de todo o tipo) do circuito, enleiam-se mais e mais nas teias" (FLOR, 2007, p. 15-16). Prates (2008), por sua vez, toma como objeto de estudo o que denominou de "Complexo W.I.T.C.H." (desenho animado, revistas, manuais, talismãs, poçóes e adereços), demonstrando as inúmeras, minuciosas e sofisticadas táticas adotadas (apresentadas no próximo item) para que as jovens meninas, atraídas pelo crescente repertório de artefatos do complexo, permaneçam atreladas a sua rede de consumo.

Carvalho (2002), ao analisar o McDonald's, faz uso do entendimento teórico de imagens pós-fotográficas ${ }^{9}$. Conforme o autor, as imagens pós-fotográficas permitem que o sujeito interaja com elas, colaborando assim para a criação de uma cultura, no caso, de uma cultura do McDonald's. Nessa perspectiva, os sujeitos contemporâneos adentram no mundo do McDonald's, e por meio de seus artefatos - como caixas de lanche e jogo americano - elaborados a partir de imagens produzidas graficamente, acabam sendo educados de acordo com os objetivos da empresa. Ao compreender que a sociedade do espetáculo produz sua própria pedagogia e que os artefatos da rede McDonald's operam como liçóes pedagógicas, Carvalho (2002, p. 42) afirma que a empresa:

[...] construiu e estabeleceu um sistema de comunicação com a sociedade através de formas simbólicas, em nosso caso [no caso 
da análise que o autor faz], através de imagens, que trazem à nossa cultura conceitos, valores, ensinamentos e versóes sobre múltiplos aspectos de nossa vida sócio-cultural.

É por meio da construção destes complexos, deste universo imagético e comercial, que as pedagogias culturais são colocadas em operação. É a inserção dos sujeitos neste universo de imagens, espetáculo e convocaçóes irrecusáveis que faz com que eles aprendam sobre si, sobre os outros, sobre o mundo e sobre tudo aquilo que tais complexos consideram desejável para que seus conglomerados se mantenham lucrativos e alinhados ao capitalismo neoliberal contemporâneo.

\section{Pedagogias Culturais e cuidados de si}

O terceiro modo que pesquisadores adotam para mostrar como operam as pedagogias culturais inspira-se nos estudos foucaultianos. Nessas pesquisas, as práticas apontadas como indicativas das pedagogias culturais dizem respeito aos cuidados/técnicas de si, ao governo das condutas, à produção de subjetividades. Tal modo, segundo Fischer (1996), faz parte da função da mídia de formar seus leitores/telespectadores, enfim, seu público. De acordo com a autora:

Ao lado de uma função objetiva de informar e divertir telespectadores, por exemplo, haveria na mídia uma função explícita e implícita de "formá-los", e isso em nossos dias não escapa à produção e veiculação de técnicas e procedimentos voltados para a relaçáo dos indivíduos consigo mesmos, matéria-prima de grande parte dos produtos televisivos e das matérias de jornais e revistas. (FISCHER, 1996, p. 174).

Alinhada com esta perspectiva, em sua tese, Thoma (2002, p. 97) destaca que o cinema é um dos dispositivos contemporâneos que molda identidades e, por isso, "a pedagogia cultural do cinema ocorre, entâo, através das liçóes sobre como devemos ser, agir, pensar e nos comportar frente a nós mesmos e aos outros". Por sua vez, Ferrari (2009, p. 26), em sua pesquisa, afirma que a pedagogia cultural na revista que analisa, Você S/A, opera "a partir do momento em que, corporificando uma cultura de negócios, criando ferramentas e estratégias de gestão, descreve e prescreve comportamentos, atitudes e dimensões da própria aparência pessoal para os candidatos a empregos".

No já mencionado estudo de Prates (2008), ao tomar como objeto de análise o que denominou de "Complexo W.I.T.C.H.", a pesquisadora vai demonstrando o modo como tal complexo opera para que as jovens meninas, fascinadas consumidoras dos 
artefatos do complexo, atuem sobre si mesmas a partir dos ensinamentos por eles veiculados. A autora ainda destaca que "ao esmiuçar as táticas dessa pedagogia cultural", reforçada, inclusive, por livretos do tipo "manual de conduta", foi possível perceber "um certo tipo de tecnologia do eu funcionando, e também algumas dimensóes de um processo de subjetivação que vai formando consumidores" (PRATES, 2008, p. 145). Foi a partir desses dois pontos, tecnologias do eu e processos de subjetivação, que a autora, ao longo de seu trabalho, argumenta no sentido de evidenciar a produtividade da mídia e das pedagogias culturais na formação de sujeitos jovens. A autora assim descreve o trabalho com seu objeto de estudo - o Complexo W.I.T.C.H.:

Vejo o complexo W.I.T.C.H. como uma certa modalidade de aparato pedagógico implicado nesse processo de construçáo de um sujeito de certo tipo. Considero-o como uma pedagogia cultural e entendo-o como um artefato cultural que opera sobre a vida das garotas, mediando esse processo de constituição e de composição de subjetividades e identidades em que estão implicadas experiências de si. (PRATES, 2008, p.89)

Por fim, relembramos que estes três modos foram categorizados para fins unicamente analíticos e provavelmente poderíamos esmiuçá-los muito mais.

\section{Conclusão}

Ao mergulharmos na leitura dos doze trabalhos do corpus de análise de nossa pesquisa, cujo objetivo foi verificar como os pesquisadores operam com o conceito de pedagogias culturais e o que mostram os estudos acerca das novas práticas que educam contemporaneamente, pudemos compreender o que Camozzato (2012) afirma sobre as pedagogias do presente e sua pluralização: que seus efeitos são múltiplos, que os modos de operar podem ser diversos e que, por isso, diferentes pedagogias atuam imbricadas nas culturas e sociedades em que vivemos. E é justamente por olharmos para este material de análise a partir da perspectiva dos Estudos Culturais que não falamos em pedagogia, mas em pedagogias, pois:

[...] a pluralização tem a ver com as formas do olhar. O "real", a "realidade", não é um dado apreensível de uma forma única, mas cambiável a partir de cada modo de olhar. A cada olhar a apresentaçáo da realidade tende a variar. Com isso as pedagogias se pluralizam frente às tentativas de ler, interpretar e apreender a realidade. (CAMOZZATO, 2012, p. 129). 
Devemos sublinhar que ao destacar, aqui, como as pedagogias culturais operam, estamos colocando em evidencia suas articulaçôes com a mídia, bem como estamos destacando sua produtividade e seus efeitos na produção dos sujeitos contemporâneos. Quer dizer, educação e comunicação atuando em sintonia, na mesma direção. Seja por meio da representação de modos desejáveis de ser sujeito, seja pela criação de redes mercantis que nos atraem e capturam, ou por um universo imagético que nos educa, seja mediante discursos e práticas que objetivam conduzir nossas condutas, o que se percebe é que grande parte dos pesquisadores conseguem reunir, apresentar e discutir evidências de que as pedagogias culturais praticadas por artefatos midiáticos são, certamente, poderosos modos de educar, de formar sujeitos sob medida para as sociedades capitalistas contemporâneas. Por isso mesmo, elas exigem um olhar ainda mais minucioso, mais aguçado, com métodos muito peculiares e em constante reconfiguração. Pensamos que os trabalhos analisados constituem empreendimentos desse tipo. Conforme Kellner (2001, p 12), "o melhor modo de desenvolver teorias sobre mídia e cultura é através de estudos específicos dos fenômenos concretos contextualizados nas vicissitudes da sociedade e da história contemporâneas".

Assim, ao se vislumbrar as pedagogias culturais como manifestação da produtiva conjunção entre educação e comunicação, foi também possível perceber a fecundidade das teorias. Elas funcionaram como novas lentes para enxergar e analisar o trepidante, inquieto e fluido mundo contemporâneo, e precisamos sempre de novos modos de evidenciar as relaçóes e articulaçóes que nos produzem, novas maneiras de compreender como chegamos a ser o que somos.

\section{Notas}

1 A publicação da obra mundialmente conhecida de Comenius, a Didactica Magna (versão latina da Didática tcheca, de 1627), ocorre em 1638. Seus escritos abrangem o período de 1612 a 1668.

${ }^{2}$ Seguimos aqui o entendimento de Narodowski (2001, p. 16) quando afirma que "A pedagogia comeniana implanta uma série de dispositivos discursivos sem os quais é praticamente impossível compreender a maior parte das posiçóes pedagógicas atuais. Evidenciam isso, entre outros postulados de Comenius, as disposiçóes universalizantes e homogeneizantes dos saberes - como: "ensinar tudo a todos" e "colocar ordem em tudo" - presentes até hoje em concepçôes de educação escolar assentadas, por exemplo, sobre as disciplinas, que dispóem sobre os saberes e sua ordenação.

${ }^{3}$ Uma das limitaçôes que encontramos no uso do Banco de Teses e Dissertações da CAPES foi que ele restringe a menção a apenas três palavras-chave. Constatamos que nas versões online completas dos trabalhos algumas vezes constavam, em quarto ou 
quinto lugar, as palavras-chave que procurávamos, o que teria expandido nossa amostra.

4 David Trend (1992) apresenta os pensamentos de Gramsci e Bourdieu cronologicamente próximos não porque desconhece que os artigos de Gramsci foram escritos antes da Segunda Guerra Mundial, mas porque sabe que só após este período é que estes foram publicados e tornaram-se conhecidos na academia.

5 Publicado originalmente em 1992, no livro Teaching against the grain: texts for a pedagogy of possibility. Traduzido por Tomaz T. da Silva e publicado em 1995 no livro Alienígenas na sala de aula (SILVA, 2008).

${ }^{6}$ Publicado pela primeira vez em 1993, na revista Socialist Review. Este artigo também foi traduzido e publicado no livro Alienígenas na sala de aula, organizado por Silva (2008).

${ }^{7}$ Traduzido e publicado no Brasil em 2001 com o título Cultura infantil: A construçâo corporativa da infância.

${ }^{8}$ A maioria das pesquisas desenvolveu-se em Programas de Pós-Graduação (PPGs) em Educação, mas há também pesquisas desenvolvidas em PPGs de Teologia e Ciências do Movimento Humano.

${ }^{9} \mathrm{O}$ paradigma pós-fotográfico refere-se a imagens produzidas por computação gráfica.

\section{REFERÊNCIAS}

CAMBI, Franco. História da Pedagogia. Tradução de Álvaro Lorencini. São Paulo: Editora da Unesp, 1999.

CAMOZZATO, Viviane Castro. Da pedagogia às pedagogias: formas, ênfases e transformaçóes. 2012. 203f. Tese (Doutorado em Educação) - Universidade Federal do Rio Grande do Sul, Porto Alegre, 2012.

CAMOZZATO, Viviane Castro; COSTA, Marisa Vorraber. Vontade de pedagogia pluralização das pedagogias e condução de sujeitos. Cadernos de Educação, Pelotas, RS, n. 44, jan./abr. 2013a. Disponível em:

<http://periodicos.ufpel.edu.br/ojs2/index.php/caduc/article/viewFile/2737/2489>. Acesso em: 20 jun. 2013

CAMOZZATO, Viviane Castro; COSTA, Marisa Vorraber. Da pedagogia como arte às artes da pedagogia. Pro-posiçóes, Campinas, SP, v. 23, n. 3, set/dez. 2013b.

CARVALHO, Alexandre Filordi de. Além dos arcos dourados: a pedagogia cultural do McDonald's. 2002. Dissertação (Mestrado em Educação) - Universidade Estadual de Campinas, Campinas, SP, 2002. 
CARVALHO, Francisco de Assis Silva. Ensina-me a morrer: cinema ensinando sobre a eutanásia. 2011. Dissertação (Mestrado em Educação) - Universidade Luterana do Brasil, Canoas, RS, 2011.

FENSTERSEIFER, Cristiane. Liçóes de natureza no Sitio do Pica-Pau amarelo. 2005. 122f. Dissertação (Mestrado em Educação) - Universidade Federal do Rio Grande do Sul, Porto Alegre, 2005.

FERRARI, Fernanda da Luz. Você S.A.: um estudo da produção de "profissionais adequados" nas matérias sobre seleção de pessoal.2009. Dissertação (Mestrado em Educação) - Universidade Luterana do Brasil, Canoas, 2009.

FIGUEIRA, Marcia Luiza Machado. Representaçôes do corpo adolescente feminino na Revista Capricho: saúde, beleza e moda. 2003. 171f. Dissertação (Mestrado em Ciências do Movimento Humano) - Universidade Federal do Rio Grande do Sul, 2003.

FISCHER, Rosa Maria Bueno. Adolescência em discurso: mídia e produção de subjetividade. 1996. 297f. Tese (Doutorado em Educação) - Universidade Federal do Rio Grande do Sul, Porto Alegre, 1996.

FISCHER, Rosa Maria Bueno. O estatuto pedagógico da mídia: questóes de análise. Educação \& Realidade, Porto Alegre, RS, v. 22, n. 22, p. 59-80, jul./dez. 1997.

FLOR, Douglas. A convocação para o consumo nas pedagogias culturais: circuitos e teias do Complexo Rebelde. 2007. Dissertação (Mestrado em Educação) Universidade Luterana do Brasil, Canoas, 2007.

GALCOWSKI, Anderson Nereu. A contracepção nas páginas da Capricho: os discursos concernentes à contracepção reverberados pela revista Capricho no ano de 1994. 2011. Dissertação (Mestrado em Teologia) - Escola Superior de Teologia, São Leopoldo, RS, 2011.

GIROUX, Henry. Doing Cultural Studies: youth and the challenge of pedagogy. Harvard Educational Review, Cambridge, v. 64, n. 3, p. 278-308, fall 1994.

Disponível em:

$<$ http://www.henryagiroux.com/online_articles/doing_cultural.htma $>$. Acesso em: 10 jan. 2013

GIROUX, Henry. Memória e Pedagogia no maravilhoso Mundo da Disney. In: SILVA, Tomas da (Org.). Alienígenas na sala de aula: uma introdução aos estudos culturais em educação. 7. ed. Petrópolis, RJ: Vozes, 2008. p. 132-158 
GIROUX, Henry; MCLAREN, Peter. Por uma pedagogia crítica da representação. In: SILVA, Tomaz Tadeu; MOREIRA, Antônio Flávio (Org.). Territórios contestados: o currículo e os novos mapas culturais. Petrópolis: Vozes, 1995. p. 144-158

KELLNER, Douglas. A cultura da mídia - estudos culturais: identidade e política entre o moderno e o pós-moderno. Trad. Ivone Castilho Benedett. Bauru, SP: EDUSC, 2001

KELLNER, Douglas. Lendo imagens criticamente: em direçáo a uma pedagogia pós-moderna. In: SILVA, Tomaz Tadeu da (Org.). Alienígenas na sala de aula: uma introdução aos estudos culturais em educação.7. ed. Petrópolis, RJ: Vozes, 2008. p. 104-131

LARROSA, Jorge. Tecnologias do eu e educação. In: SILVA, Tomaz Tadeu da (Org.). O sujeito da educação: estudos foucaultianos. Petrópolis, RJ: Vozes, 1994. p. 35-86.

NARODOWSKI, Mariano. Comenius e a Educação. Tradução de Alfredo VeigaNeto. Belo Horizonte: Autêntica, 2001.

PRATES, Camille Jacques. O Complexo W.I.T.C.H. acionando a magia para formar garotinhas nas redes do consumo. 2008. Dissertação (Mestrado em Educação) Universidade Luterana do Brasil, Canoas, RS, 2008.

SANTOS, Denise Preussler dos. Revistas institucionais também ensinam? O caso da revista Indústria Brasileira. 2011. Dissertação (Mestrado em Educação) Universidade Luterana do Brasil, Canoas, RS, 2011.

SILVA, Halan Kardeck Ferreira. Uma pedagogia cultural militante: representaçóes e identidades do vaqueiro no Cinema Novo. 2010. Dissertação (Mestrado em Educação) - Universidade Luterana do Brasil, Canoas, RS, 2010.

SILVA, Tomaz Tadeu; MOREIRA, Antônio Flávio (Org.). Territórios contestados: o currículo e os novos mapas culturais. Petrópolis: Vozes, 1995.

SILVA, Tomaz Tadeu da. Teoria Cultural e Educação: um vocabulário crítico. Belo Horizonte: Autêntica, 2000.

SILVA, Tomaz Tadeu. Alienígenas na sala de aula: uma introdução aos estudos culturais em educação. 7. ed. Petrópolis, RJ: Vozes, 2008.

SIMON, Roger. A pedagogia como uma tecnologia cultural. In: SILVA, Tomaz Tadeu. Alienígenas na sala de aula: uma introdução aos estudos culturais em educação. 7. ed. Petrópolis, RJ: Vozes, 2008. p. 61-84. 
STEINBERG, Shirley; KINCHELOE, Joe (Orgs). Cultura Infantil: a construção corporativa da infância. Tradução de George Eduardo Japiassú Brício. 2. ed. Rio de Janeiro: Civilização Brasileira, 2004.

THOMA, Adriana da Silva. O cinema e a flutuação das representaçôes surdas: "que drama se desenrola neste filme? Depende da perspectiva...”. 2002. 259f. Tese (Doutorado em Educação) - Universidade Federal do Rio Grande do Sul, Porto Alegre, 2002.

TREND, David. Cultural Pedagogy: art, education, politics. New York: Bergin \& Garvey, 1992.

WOODWARD, Kathryin. Identidade e diferença: uma introdução teórica conceitual. In: SILVA, Tomaz Tadeu da (Org.). Identidade e diferença: a perspectiva dos Estudos Culturais. 7. ed. Petrópolis, RJ: Vozes, 2007. p. 7-72.

WORTMANN, Maria Lúcia Castagna. (Re)inventando a Educação a partir dos Estudos Culturais: notas sobre a articulação desses campos no ambiente universitário gaúcho. In: SARAIVA, Karla; MARCELLO, Fabiana de Amorim (Org.). Estudos Culturais e Educação: desafios atuais. Canoas, RJ: Editora da ULBRA, 2012. p. 111133. 


\section{In the productive confluence between education and com- munication, the contemporary cultural pedagogies}

\section{Abstract}

The article presents a discussion about the productivity of the Cultural Pedagogies concept under Brazilian studies that bring together education and communication. It analyzes, in theses and dissertations, how researchers operate with the concept and what they can show on how the pedagogies that form the subject of the present engender. The corpus of analysis was composed by twelve papers collected in the database of theses and dissertations from CAPES. The theoretical referential of the study is subsidized by authors that deal with pedagogy and cultural pedagogies as Jorge Larrosa (1994), Steinberg and Kincheloe (2004), Giroux (1994), Fischer (1997) and Camozzato (2012), among others. The analysis results were joined into three operating modes of cultural pedagogies pointed in the investigated researches: a) representation of diferents modes a subject can be; b) activation of midiatic complex market; c) activation of selfcare techniques.

Keywords: Communication and Education. Cultural Pedagogy. Media and Education.

\section{Productiva confluencia entre educación y comunicación: las pedagogías culturales con- temporáneas}

\section{Resumen}

El artículo presenta una discusión sobre la productividad del concepto de pedagogías culturales en los estudios brasileños que aproximan la educación y la comunicación. Anali$\mathrm{za}$, en tesis y disertaciones, como los investigadores trabajaron con este concepto y como ellos consiguen mostrar las maneras en que se engendran las pedagogías que forman los sujetos en el presente. El cuerpo de análisis fue compuesto por doce artículos colectados en la base de datos de tesis y disertaciones de la CAPES. El marco teórico del estudio está referenciado por los autores que se ocupan de la pedagogía y las pedagogías culturales como Jorge Larrosa (1994), Steinberg y Kincheloe (2004), Giroux (1994), Fischer (1997) y Camozzato (2012), entre otros. Los resultados del análisis fueron agrupadas en tres modos de funcionamiento de las pedagogías culturales a partir de las investigaciones analizadas: a) representación de los modos de ser del sujeto; b) la activación del mercado de medios complejos; c) la activación de las técnicas de autocuidado.

Palabras claves: Comunicación y Educación. Pedagogía Cultural. Medios y Educación. 


\section{Marisa Vorraber Costa}

E-mail:vorrabercosta@gmail.com

\section{Paula Deporte de Andrade}

E-mail: paula.deporte@hotmail.com

Recebido em: 11/02/2014

Aprovado em: 27/03/2014 